\title{
BMJ Open Topical or oral antibiotics for children with acute otitis media presenting with ear discharge: study protocol of a randomised controlled non-inferiority trial
}

\author{
Saskia Hullegie (D) , ${ }^{1}$ Roderick P Venekamp (D) , ${ }^{1}$ Thijs M A van Dongen, ${ }^{1}$ \\ Sanne Mulder, ${ }^{2}$ Willem van Schaik, ${ }^{3}$ G Ardine de Wit, ${ }^{1,4}$ Alastair D Hay, ${ }^{5}$ \\ Paul Little (10), ${ }^{6}$ Michael V Moore (1) , ${ }^{6}$ Elisabeth A M Sanders, ${ }^{7,8}$ \\ Marc J M Bonten, ${ }^{1,9}$ Debby Bogaert, ${ }^{7,10}$ Anne GM Schilder, ${ }^{1,11,12}$ \\ Roger A M J Damoiseaux ${ }^{1}$
}

To cite: Hullegie S, Venekamp RP, van Dongen TMA, et al. Topical or oral antibiotics for children with acute otitis media presenting with ear discharge: study protocol of a randomised controlled non-inferiority trial. BMJ Open 2021;11:e052128. doi:10.1136/ bmjopen-2021-052128

- Prepublication history and additional supplemental material for this paper are available online. To view these files, please visit the journal online (http://dx.doi.org/10.1136/ bmjopen-2021-052128)

Received 06 April 2021 Accepted 26 November 2021

Check for updates

(c) Author(s) (or their employer(s)) 2021. Re-use permitted under CC BY-NC. No commercial re-use. See rights and permissions. Published by BMJ.

For numbered affiliations see end of article.

Correspondence to

Ms Saskia Hullegie;

s.hullegie@umcutrecht.nl

\section{ABSTRACT}

Background Around $15 \%-20 \%$ of children with acute otitis media present with ear discharge due to a spontaneous tear or perforation of the eardrum (AOMd). Current guidance recommends clinicians to consider oral antibiotics as first-line treatment in this condition. The opening in the eardrum however should allow topical antibiotics to enter the middle ear directly. Local administration of antibiotics does not expose children to systemic side effects and may put less selective resistance pressure on bacteria. Evidence on the effectiveness of this approach in children with AOMd is lacking.

Methods and analysis A primary care-based, open, individually randomised, controlled, non-inferiority trial. The trial aims to recruit 350 children aged 6 months to 12 years with AOMd and ear pain and/or fever. Participants will be randomised to 7 days of hydrocortisone-bacitracincolistin eardrops five drops three times daily or amoxicillin oral suspension $50 \mathrm{mg} / \mathrm{kg}$ body weight per day, divided over three doses. Parents will keep a daily diary of AOM symptoms, adverse events and complications for 2 weeks. In addition, they will record AOM recurrences, healthcare utilisation and societal costs for 3 months. The primary outcome is the proportion of children without ear pain and fever at day 3. Secondary outcomes include ear pain and fever intensity/severity; days with ear discharge; eardrum perforation at 2 weeks; adverse events during first 2 weeks; costs; and cost effectiveness at 2 weeks and 3 months. The primary analyses will be intention-to-treat and per-protocol analyses will be conducted as well.

Ethics and dissemination The medical research ethics committee Utrecht, The Netherlands has given ethical approval (17-400/G-M). Parents/guardians of participants will provide written informed consent. Study results will be submitted for publication in peer-reviewed medical journals and presented at relevant (inter)national scientific meetings.

Trial registration number The Netherlands National Trial Register; NTR6723. Date of registration: 27 November 2017.
Strengths and limitations of this study

- The pragmatic, open-label design of our trial enhances the applicability of the findings to daily practice.

- The pragmatic design is most suited to address key secondary outcomes such as antibiotic consumption during the first 2 weeks and cost-effectiveness in everyday practice.

- The open-label design may introduce bias caused by the awareness of treatment assignment.

\section{INTRODUCTION}

Acute otitis media (AOM) is one of the most common childhood infections and an important reason for doctor consultations and antibiotic prescribing. ${ }^{2}$ Approximately $15 \%-20 \%$ of children with AOM present with ear discharge due to a spontaneous tear or perforation of the eardrum (AOMd). ${ }^{34}$ Contrary to widespread beliefs, children with AOMd have similar levels of ear pain and are more unwell at presentation than those without ear discharge. ${ }^{34}$ These children also have a poorer prognosis with higher rates of ear pain and/or fever at 3-7 days and more AOM recurrences and hearing problems at 3 months than children presenting with AOM without ear discharge. ${ }^{3}{ }^{4}$ They also benefit more from oral antibiotics than those with $\mathrm{AOM}$ without ear discharge: number needed to treat to achieve resolution of ear pain and/or fever at days 3-7: 3 versus 8, respectively. ${ }^{3}$ Based on this evidence, current guidelines recommend general practitioners (GPs) to consider an immediate oral antibiotic prescribing strategy for children with AOMd. ${ }^{56}$ Oral antibiotics, however, expose children to systemic side effects such as 
diarrhoea, vomiting and $\operatorname{rash}^{7}$ and routine use of oral antibiotics in common infections such as AOM contributes to emergence of antimicrobial resistance. ${ }^{89}$ Alternative treatment strategies for $\mathrm{AOM}$ are therefore urgently needed.

In children with $\mathrm{AOMd}$, the perforation should allow topical antibiotics to enter the middle ear directly. Topical antibiotic treatment does not expose children to systemic side effects and may put less selective resistance pressure on commensal microbes. ${ }^{1011}$ We have shown that in children with acute ear discharge in the presence of ventilation tubes (grommets) antibiotic-corticosteroid eardrops are clinically much more effective and less costly than oral antibiotics. ${ }^{12}{ }^{13}$ Topical antibiotics may therefore also be an effective treatment strategy in children with AOMd. So far, evidence to support this hypothesis is lacking. ${ }^{14} 15$ Our trial aims to provide this key evidence.

\section{OBJECTIVE}

The aim of this randomised controlled trial is to establish whether treatment with antibiotic-corticosteroid eardrops is non-inferior to treatment with oral antibiotics in children aged 6 months to 12 years presenting to their GP with AOM with acute ear discharge due to a spontaneous tear or perforation of the eardrum (AOMd).

The objectives are to determine the:

- Effectiveness of antibiotic-corticosteroid eardrops versus oral antibiotics in terms of:

- The proportion of children without ear pain and fever at day 3 ;

- Severity and duration of ear pain, fever, ear discharge;

- Time to resolution of total symptoms;

- Middle ear effusion (MEE) and eardrum perforation at 2 weeks;

- Otitis media (OM)-specific quality of life (QoL) at 2 weeks and 3 months;

- Antibiotic consumption during the first 2 weeks and at 3 months and AOM recurrences at 3 months;

- Adverse events during the first 2 weeks;

- Costs and cost-effectiveness of antibiotic-corticosteroid eardrops versus oral antibiotics;

- Prevalence of bacteria and viruses in otorrhoea and nasopharyngeal samples of children with AOMd before and after treatment and the antimicrobial susceptibility profile of the bacteria;

- Impact of the treatment regimens on antimicrobial resistance genes in the human gut.

\section{METHODS AND ANALYSES}

\section{Study design and setting}

An open, individually randomised, controlled, noninferiority trial in 350 children aged 6 months to 12 years presenting to their GP with AOMd. Children will be randomly allocated to 7 days treatment with either: (1) antibiotic-corticosteroid

\section{Box 1 Full list of inclusion and exclusion criteria}

\section{Inclusion criteria:}

Children aged 6 months to 12 years whose parents are consulting the general practitioner (GP) with acute otitis media (AOM) and ear discharge in one or both ears ( $\leq 7$ days duration) and either parent-reported ear pain in the previous 24 hours or fever (child's body temperature of $\geq$ $38.0^{\circ} \mathrm{C}$ in the previous 24 hours as reported by parents or as measured by the GP during consultation) or both.

\section{Exclusion criteria:}

Children will be excluded from participation if they;

1. Are systemically very unwell and require immediate oral antibiotics or immediate hospitalisation (eg, child has signs and symptoms of serious illness and/or complications such as mastoiditis/meningitis);

2. Are at high risk of serious complications including children with known immunodeficiency other than partial IgA or IgG2 deficiencies, craniofacial malformation such as cleft palate, children with Down syndrome, previous ear surgery other than grommet insertion;

3. Have grommets in place;

4. Have a pre-existing perforation of the eardrum;

5. Had a prior AOM episode (with or without ear discharge) in previous 28 days;

6. Used oral antibiotics or topical antibiotics in previous 2 weeks;

7. Have a known allergy or sensitivity to oral amoxicillin or hydrocortisone-bacitracin-colistin;

8. Have already participated in this trial.

(hydrocortisone-bacitracin-colistin) eardrops or (2) oral antibiotics (amoxicillin suspension). Follow-up will be 3 months.

At trial commencement, in December 2017, we anticipated a 2-year trial recruitment period. Approximately 250 GPs in the region of Utrecht, The Netherlands, agreed to recruit children to the trial. Due to the COVID-19 related infection control measures, we anticipate a relatively low AOM incidence during trial recommencement. To meet the required sample size, we will recruit additional general practices to the trial. Further details on the trial status are outlined in the 'current study status' section below.

\section{Participants}

Children aged 6 months to 12 years presenting to their GP with recent onset AOMd in one or both ears and either ear pain or fever or both. Children with grommets in place and those with a pre-existing perforation of the eardrum are excluded. For detailed inclusion and exclusion criteria, see box 1 .

AOM presenting with ear discharge due to a spontaneous tear or perforation of the eardrum (AOMd) is defined as the presence of acute-onset of otoscopically confirmed otorrhoea together with other symptoms of an acute infection such as ear pain and/or fever, and/or irritability.

\section{Inclusion and baseline assessments}

Figure 1 depicts a flow diagram of study procedures. Participating GPs inform parents of potentially eligible children about the trial, take consent for sharing their contact details with the research team at the UMC 


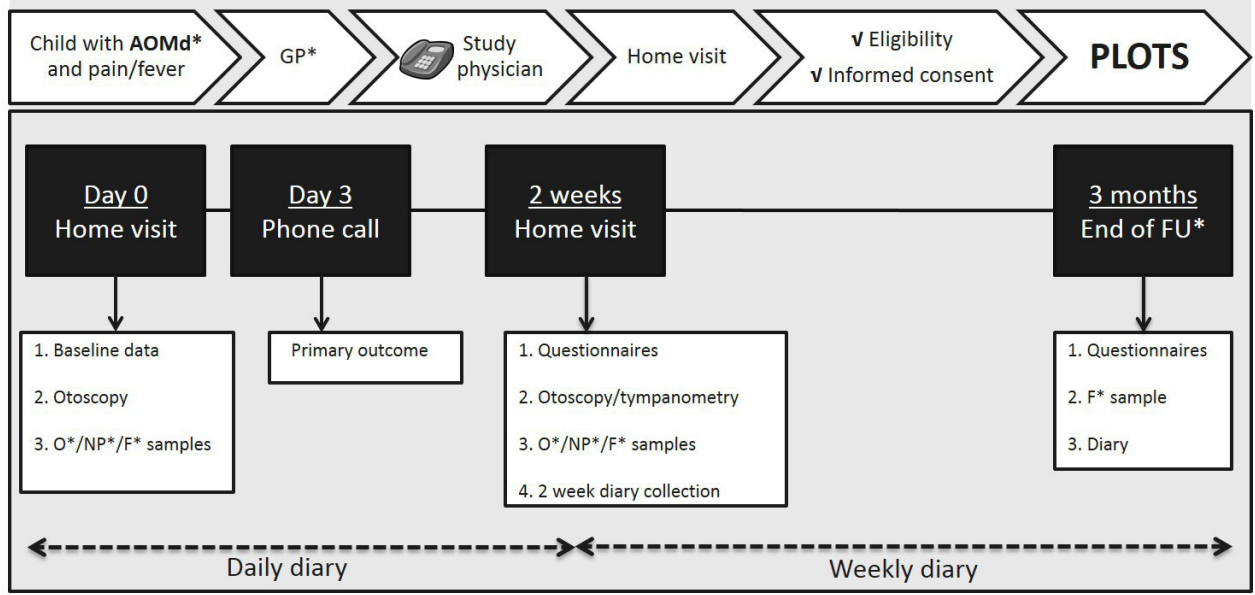

Figure 1 Flow diagram of main study procedures. AOMd; acute otitis media with ear discharge, GP; general practitioner, O; otorrhoea, NP; nasopharynx, F; faeces, FU; follow-up.

Utrecht and provide a study information letter. Members of the research team contact parents by phone to provide detailed information about the trial. If parents provisionally agree to participate and if the child meets the eligibility criteria, a home visit by the trial doctor is scheduled for the same day.

At this visit, the trial doctor takes written informed consent from parents/guardians, collects baseline demographic and disease-specific data, records otoscopic findings and takes otorrhoea, nasopharynx and faeces samples. Parents will complete an OM-specific QoL questionnaire on behalf of their child.

\section{Study group assignment}

An independent data manager generates a computergenerated randomisation sequence with stratification according to age ( $<2$ vs $\geq 2$ years) and laterality (unilateral vs bilateral AOM at baseline). At the conclusion of the baseline home visit, the trial doctor accesses a trial randomisation website for concealed study-group assignment. The assignment will be balanced in a 1:1 ratio for the two study groups:

1. Hydrocortisone-bacitracin-colistin (Bacicoline-B) eardrops, five drops, three times per day in the discharging ear(s) for 7 days; or

2. Amoxicillin, $50 \mathrm{mg} / \mathrm{kg}$ of body weight per day, divided over three doses administered orally for 7 days.

Hydrocortisone-bacitracin-colistin eardrops are the most widely used commercially available eardrops in the Netherlands that do not contain a potentially ototoxic aminoglycoside. The combination of antibiotics in these eardrops covers the spectrum of bacteria most often found in AOM. ${ }^{16}{ }^{17}$ We have chosen an eardrop that also contains a corticosteroid since the available evidence from children with grommets suggests that topical treatment with a combination of antibiotics and a corticosteroid might be more effective than topical antibiotics alone in resolving acute ear discharge. ${ }^{18} 19$
Hydrocortisone-bacitracin-colistin eardrops were also used in our previous trial in children with acute ear discharge in the presence of ventilation tubes (grommets). ${ }^{12}$ Parents of children assigned to the antibioticcorticosteroid eardrops group will be shown how to remove any visible ear discharge with a tissue and apply the drops while tilting their child's head to one side, and to apply tragal pressure (tragal pumping).$^{20}$

Amoxicillin is listed as first-line antibiotic for AOM in children in most European guidelines, including the Netherlands. ${ }^{621}$ Based on the current antimicrobial resistance profiles in the Netherlands, the clinical practice guideline refers to the Dutch Paediatric Formulary which recommends a dosage of $50 \mathrm{mg} / \mathrm{kg}$ of body weight per day, divided over three doses for 7 days. ${ }^{622}$

The study team will notify the GP and local pharmacist about the result of the randomisation. During follow-up, parents and GPs are encouraged to manage AOM recurrences according to current Dutch clinical practice guidance ${ }^{6}$ but any treatment decisions will be up to the GPs' discretion. Being a pragmatic trial, no restrictions in concurrent treatment will be applied and any concurrent treatments will be captured in the daily symptom diary.

\section{Follow-up data collection}

Participants will be followed for 3 months. Parents will keep a daily diary of AOM-related symptoms including fever recordings and ear pain scores, use of study and other medication, adverse events and complications of AOM for 2 weeks. Thereafter, they will keep a weekly diary recording AOM recurrences, GP consultations, prescribed and over-the-counter (OTC) medication, hospital admissions and societal costs for AOM for 3 months. A telephone call will be scheduled at day 3 to answer any remaining questions about the study, to optimise compliance to the diary and to capture data on our most critical parent-reported outcomes. A follow-up visit at the child's home will be scheduled at 2 weeks to check 
diary data for accuracy, perform otoscopy and tympanometry and sample otorrhoea (where possible), nasopharynx and faeces samples. Parents will complete OM-specific QoL and productivity loss questionnaires at 2 weeks and at 3 months. Parents will also send a faeces sample to the laboratory for analysis at 3 months.

\section{Validated questionnaires}

Parents report the presence and severity of their child's symptoms using a validated seven-point Likert scale. ${ }^{23} 24$ OM-specific QoL of the child will be assessed using the parent-reported OM-6 questionnaire, a 6-item questionnaire recording ear-related problems in the previous period. ${ }^{25}$ An adapted version of the $i$ MTA Productivity Cost Questionnaire ( $2 \mathrm{PCQ})$ is used to capture parental productivity losses due to $\mathrm{AOM}^{26}$

\section{Temperature measurement}

Parents measure their child's temperature two times per day (morning and evening) with a tympanic membrane thermometer in the unaffected ear. ${ }^{27}$ In children aged below 2 years and in those with bilateral ear discharge, temperature is measured rectally. To standardise measurements, a study thermometer will be provided. The definition of 'no fever' at day 3 (primary outcome) is a temperature recording below $38.0^{\circ} \mathrm{C}$ both in the morning and evening. ${ }^{6}$

\section{Eardrum perforation}

Otoscopy will be used to assess the integrity of the eardrum at 2 weeks. In case of inconclusive otoscopy results, tympanometry results will be used.

\section{MEE assessment}

A diagnostic algorithm combining tympanometry and otoscopy will be used to diagnose MEE at 2 weeks. ${ }^{28}$

\section{Collection and analyses of otorrhoea and nasopharynx samples}

The otorrhoea and nasopharynx samples are collected using a flexible applicator swab with flocked nylon fibre tip. ${ }^{29}$ The swabs will be immediately transported to the microbiology laboratory of the UMC Utrecht where they will be stored at $-80^{\circ} \mathrm{C}$ until further analysis.

\section{Collection and analyses of faeces samples}

The baseline, 2-week and 3-month faeces samples are collected using the OMNIgeneOGUT (OMR-200), a trademark of DNA Genotek, Ottawa, Canada. Parents will send the 3-month faeces samples by mail. If faeces samples cannot be collected during the baseline and 2-week home visit, we will provide the parents with a collection kit and transport envelop, so parents can collect and send the faeces samples by mail at their earliest convenience. Samples will be stored at $-80^{\circ} \mathrm{C}$ at the microbiology laboratory of the UMC Utrecht until analysis for detection and quantification of the dynamics of bacterial genes that confer resistance to the antibiotics used in our trial. ${ }^{30}$

\section{Primary and secondary outcomes}

The primary outcome is the proportion of children without ear pain (ear pain score 0 on the $0-6$ Likert scale) and fever (body temperature of $38.0^{\circ} \mathrm{C}$ or higher) at day 3 (72 hours after randomisation).

Secondary outcomes are the proportion of children with at most mild ear pain (ear pain score less than 3 on the 0-6 Likert Scale) at day 3; mean ear pain score over days $0-3$, number of days with ear pain (ear pain score 1 or higher on the $0-6$ Likert scale); mean body temperature over days $0-3$; number of days with fever (body temperature of $38.0^{\circ} \mathrm{C}$ or higher) during the first 2 weeks; the proportion of children with parentreported ear discharge at day 3; number of days with parent-reported ear discharge at day 3 and during the first 2 weeks; proportion of children with otoscopically confirmed ear discharge at 2 weeks; time to resolution of total symptoms (time to all of pain, fever, discharge, being unwell, sleep disturbance, and distress/crying being rated 0 or 1 on the Likert scale); MEE and proportion of children with otoscopically confirmed eardrum perforation at 2 weeks; OM-specific QoL at baseline, 2 weeks and 3 months; antibiotic consumption during the first 2 weeks and at 3 months; number of AOM recurrences at 3 months; number of adverse events during the first 2 weeks; costs and cost-effectiveness at 2 weeks and 3 months; the prevalence of viruses and bacteria in otorrhoea and nasopharynx samples at baseline and 2 weeks; the antimicrobial susceptibility profiling of the bacteria and the impact of the treatment regimens on antimicrobial resistance genes in the human gut; microbiome profile of nasopharynx at baseline and 2 weeks.

\section{Sample size calculation}

The main aim is to demonstrate that antibioticcorticosteroid eardrops are non-inferior to oral antibiotics in relieving ear pain and fever at day 3 . The proportion of children without ear pain and fever at day 3 is expected to be $65 \%$ in the oral antibiotics group and around $35 \%$ if placebo or no treatment would be trialled. ${ }^{3}$ Our parent panel assisted in defining the non-inferiority margin by advising on the maximum difference in primary outcome that they would regard as unimportant. Following these discussions, the clinically acceptable non-inferiority margin is set at $15 \%$; that is, $50 \%$ of the difference $(30 \%)$ observed between oral antibiotics and placebo or no treatment in earlier trials. ${ }^{3}$ Taking $50 \%$ of such a difference is also a widely-accepted method to determine the noninferiority margin. ${ }^{31} 32$ Testing significance at a one-sided 0.025 level $(\alpha)$ and using a power of $80 \%(\beta 0.20)$, each treatment arm should include at least 159 children to demonstrate that the upper limit of the one-sided $97.5 \%$ CI (or equivalently a two-sided 95\% CI) of the difference in treatment effect for the primary outcome does not exceed the predefined non-inferiority margin of $15 \%$. To allow for a maximum of $10 \%$ loss to follow-up, we aim to randomise 350 children. 


\section{STATISTICAL ANALYSIS}

Primarily, all analyses will be performed according to the intention-to-treat principle. Per-protocol analyses will also be conducted as well because of its importance in non-inferiority trials. ${ }^{33}$ All analyses will be performed blinded with respect to study-group assignment and analysis and presentation of results will be in accordance with the Consolidated Standards of Reporting Trials guidelines. ${ }^{3435}$

\section{Clinical effectiveness}

We will use descriptive statistics to describe the baseline characteristics trial population; we will present means and SD for normally distributed continuous variables, medians and IQRs for non-normally distributed continuous variables, and numbers with percentages for categorical variables.

The primary outcome will be analysed with binomial logistic regression model including treatment group and effectiveness of oral antibiotics versus antibioticcorticosteroid eardrops will be expressed as relative risk and absolute risk difference with accompanying 95\% CIs. This latter will enable us to judge whether non-inferiority has been demonstrated, in particular whether the upper limit of the two-sided 95\% CI exceeds the predefined non-inferiority margin of $15 \%$. In adjusted analyses, stratification factors and other important prognostic factors (baseline ear pain score, duration of ear pain prior to enrolment) will be added to the model. Subgroup effects according to age ( $<2$ vs $\geq 2$ years) and laterality (unilateral vs bilateral AOM at baseline) will be evaluated by including an interaction term (treatment*age) in the model.

In sensitivity analyses, we will impute for missing baseline and outcome data using multiple imputation techniques. ${ }^{36}{ }^{37}$ In further sensitivity analysis, we will assess whether results differ when defining the absence of fever for the primary outcome as parental fever score 0 or 1 on the 0-6 Likert scale at day 3 (instead of the child's body temperature recordings as specified above).

In secondary analysis, we will use log binomial regression analyses for dichotomous variables, Poisson regression analyses for count variables, and linear regression analyses for continuous variables, where applicable corrected for repeated measurements. For these analyses, the comparison between treatment groups will be expressed as risk ratios, rate ratios, and mean differences, respectively; all with 95\% CIs. Kaplan-Meier curves will be plotted for duration of symptoms and log-rank tests for differences between groups.

\section{Cost-effectiveness analysis}

A societal perspective will be used for this analysis, that is, medical and non-medical costs will be taken into account. We will use a short-time horizon for all analyses and therefore, all costs will be presented undiscounted.

First, effectiveness will be assessed: the main clinical effectiveness outcome will be symptom (ear pain and fever) resolution. Similar to our previous trials in this field, we will not use quality-adjusted life-years (QALYs) as the nature of the condition (self-limiting in the vast majority of the children and of relatively short duration) does not impact importantly on QALYs. ${ }^{12}$

Second, costs will be calculated; all costs will be estimated at the patient level by multiplying resource use with cost estimates per unit of resources use. Cost prices will be estimated according to guidelines for economic evaluation in healthcare research or taken from standard reference lists, as far as possible. ${ }^{3839}$ Costs of medication use will be retrieved from the Dutch formulary and a pharmacist's fee will be added for every prescription. ${ }^{38} 40$ Costs of OTC and complementary medicines will be calculated per day, based on current average retail prices. Costs of consulting a GP or a medical specialist, and hospitalisations will be based on current Dutch guidelines for pharmacoeconomic evaluation $^{38}$ or charges if no other estimates are available. Costs of diagnostic tests will also be derived from the Dutch guidelines for pharmacoeconomic evaluation. ${ }^{38}$ Costs of surgical procedures will be based on a previous Dutch costing study. ${ }^{41}$ Costs associated with absence from work will be retrieved from the completed $i \mathrm{PCQ}^{26}$ The hourly cost estimate for childcare will be derived from the Dutch National Institute for Family Finance Information. ${ }^{42}$ Travel expenses will be calculated for healthcare visits following the Dutch guideline for pharmacoeconomic evaluation. ${ }^{38}$ Overall costs will be compared across the treatment groups, and where relevant, differences will be calculated, including 95\% CIs. Finally, we will compare differences in costs between treatment groups to differences in clinical effects between groups by calculating incremental costeffectiveness ratios (ICERs). ICERs will indicate the incremental cost per day with ear pain and fever avoided when comparing antibiotic-corticosteroid eardrops with oral antibiotics, both in the short (14 days) and long term (3 months). Uncertainty will be addressed in a probabilistic sensitivity analysis by means of bootstrapping. Results will be presented using incremental cost-effectiveness planes and cost-effectiveness acceptability curves.

\section{ETHICS AND DISSEMINATION}

The study is conducted according to the principles of the Declaration of Helsinki (10th version, October 2013), in accordance with the Medical Research Involving Human Subjects Act (WMO) and the principles of Good Clinical Practice. The medical research ethics committee Utrecht, The Netherlands has approved the protocol (protocol number $17-400 / M-G)$. The trial doctor will take written informed consent (see online supplemental file 1) from both parents/guardians. Regular trial audits including checks on source data verification, accuracy, validity and completeness of informed consent forms and captured data will be performed by a clinical research associate of Julius Clinical, an independent clinical research organisation. We have not established a data safety monitoring 
board and refrain from conducting any interim analysis for safety or superiority/futility since we neither expect any safety issues nor large differences in treatment failures between the two active treatment groups given the difference $(30 \%)$ observed between oral antibiotics and placebo or no treatment in previous trials. ${ }^{212}$ However, in accordance to section 10 , subsection 4 , of the WMO, the sponsor will suspend the study if there is sufficient ground that continuation of the study will jeopardise subject health or safety. The data management department of the Julius Center for Health Sciences and Primary Care of the UMC Utrecht will be responsible for handling and storage of the data using innovative software applications like SLIM (Study Logistic and Information Management System) and Research Online. On completion of the trial, data will be stored for a minimum of 15 years at a central data drive at the Julius Center and will only be made available for use by third parties on request and approval of the principle investigator (professor RAMJD).

\section{Dissemination plan}

We will publish study results in peer reviewed scientific journals and present at relevant (inter)national scientific meetings. We will work with our parent panel to help interpret the findings of the trial and harness their resources for dissemination to the lay public.

\section{PATIENT AND PUBLIC INVOLVEMENT}

For this trial, we have established a panel of eight parents. This panel provided input to the design of the trial including the sample size calculation by advising on the clinically acceptable non-inferiority margin and the outcome measures by proposing additional outcomes of interest such as being unwell and sleep disturbance, and commented on the recruitment strategy and patient information letter. One of the parent panel members is a coapplicant on the grant application and coauthor on this paper. The parent panel will be actively involved throughout all critical stages of the trial through regular parent panel meetings. They will work with us throughout the recruitment phase, will be involved in reporting the trial results, and will be ultimately key to pull the evidence into mainstream clinical practice.

\section{CURRENT STUDY STATUS}

The first participant was enrolled in the trial on 13 December 2017. On 8 August 2018 with 34 participants being enrolled, trial recruitment was put on hold due to supply issues of hydrocortisone-bacitracin-colistin eardrops. These drops are available again since early 2021. Our funding body, the Netherlands Organisation for Health Research and Development $(\mathrm{ZonMw})$, has approved the trial to reopen in September 2021. We expect data collection to be completed by the end of 2023 with trial results being available by March 2024.

\section{DISCUSSION}

This trial is one of the first to compare the effectiveness of topical with oral antibiotics in children with AOMd. The only other trial in this field is conducted in UK primary care (Runny Ear STudy). This study has been designed in close collaboration with members of the Dutch study team to enable future meta-analysis by harmonising design, outcomes and outcome measure instruments. ${ }^{14} 15$ The UK-based trial has stopped prematurely due to problems with the electronic health record system platform which resulted in low recruitment $(n=22)$ and failure to reach the predefined sample size. $^{43}$

With obvious theoretical advantages of topical over oral antibiotic treatment and the lack of direct evidence, further research is needed to establish whether with AOMd can effectively be treated with topical antibiotics. Our trial will not only provide this key evidence, but also establish the impact of the two antibiotic treatment strategies on microbiome composition and antimicrobial resistance. The pragmatic, open-label design of our trial enhances the applicability of the findings to daily practice and is most suited to address key secondary outcomes such as antibiotic consumption during the first 2 weeks and cost-effectiveness in everyday practice. This would be much more difficult to determine realistically in a blinded study where children in both groups would receive oral suspension and ear drops. The lack of blinding might, however, introduce bias caused by the awareness of treatment assignment which may be particularly problematic in trials with subjective outcomes. However, both study groups receive an active treatment, our parent panel had no strong beliefs or preferences for one treatment over the other, and a recent meta-epidemiological study found no evidence for a difference in estimated treatment effect between blinded and non-blinded trials. ${ }^{44}$ Another limitation of our study is, that we do not capture data on the prevalence of longer term complications such as the presence of otoscopically confirmed MEE or chronic suppurative OM at 3 months. We, however, will collect information about AOM-related specialist referrals, hospitalisation and/or surgery during the 3 months follow-up period, which provide information on the occurrence of AOM sequelae in the short and long terms.

\section{Author affiliations}

${ }^{1}$ Julius Center for Health Sciences and Primary Care, University Medical Center Utrecht, Utrecht, The Netherlands

${ }^{2}$ Parent and PPI contributor, Utrecht, the Netherlands

${ }^{3}$ Institute of Microbiology and Infection, University of Birmingham, Birmingham, UK ${ }^{4}$ Centre for Nutrition, Prevention and Healthcare, National Institute of Public Health and the Environment (RIVM), Bilthoven, The Netherlands

${ }^{5}$ Centre for Academic Primary Care, School of Social and Community Medicine, University of Bristol, Bristol, UK

${ }^{6}$ Primary Care Population Science and Medical Education, Aldemoor Health Centre, University of Southampton, Southampton, UK

${ }^{7}$ Department of Paediatric Immunology and Infectious Diseases, Wilhelmina Children's Hospital, University Medical Center Utrecht, Utrecht, The Netherlands

${ }^{8}$ Centre for Infectious Disease Control, National Institute of Public Health and the Environment (RIVM), Bilthoven, The Netherlands

${ }^{9}$ Department of Medical Microbiology, University Medical Center Utrecht, Utrecht, The Netherlands

${ }^{10}$ Centre for Inflammation Research, Queen's Medical Research Institute, University of Edinburgh, Edinburgh, UK 
${ }^{11}$ National Institute for Health Research University College London Hospitals Biomedical Research Centre, London, UK

${ }^{12}$ evidENT, Ear Institute, University College London, London, UK

Acknowledgements We gratefully thank our parent panel for their valuable input and all children and parents who participated in our trial thus far.

Contributors RV, AS and RAMJD designed the trial. SH, RV and TMAvD drafted the first version of the protocol paper and AS and RAMJD provided feedback on this version. All other authors (SM, WvS, GAdW, ADH, PL, MM, ES, MJMB, DB) commented on the revised version of the protocol. All authors approved the final version of the manuscript.

Funding The trial is supported by a grant from the Netherlands Organisation for Health Research and Development (ZonMw) - Rational Pharmacotherapy 5th Open Call - grant number 848015006 .

Disclaimer The funding agency had no role in the design, data collection and analysis, decision to publish, or preparation of the manuscript.

Competing interests None declared.

Patient consent for publication Not required.

Provenance and peer review Not commissioned; externally peer reviewed.

Supplemental material This content has been supplied by the author(s). It has not been vetted by BMJ Publishing Group Limited (BMJ) and may not have been peer-reviewed. Any opinions or recommendations discussed are solely those of the author(s) and are not endorsed by BMJ. BMJ disclaims all liability and responsibility arising from any reliance placed on the content. Where the content includes any translated material, BMJ does not warrant the accuracy and reliability of the translations (including but not limited to local regulations, clinical guidelines, terminology, drug names and drug dosages), and is not responsible for any error and/or omissions arising from translation and adaptation or otherwise.

Open access This is an open access article distributed in accordance with the Creative Commons Attribution Non Commercial (CC BY-NC 4.0) license, which permits others to distribute, remix, adapt, build upon this work non-commercially, and license their derivative works on different terms, provided the original work is properly cited, appropriate credit is given, any changes made indicated, and the use is non-commercial. See: http://creativecommons.org/licenses/by-nc/4.0/.

\section{ORCID iDs}

Saskia Hullegie http://orcid.org/0000-0003-3413-1423

Roderick P Venekamp http://orcid.org/0000-0002-1446-9614

Paul Little http://orcid.org/0000-0003-3664-1873

Michael V Moore http://orcid.org/0000-0002-5127-4509

\section{REFERENCES}

1 Tong S, Amand C, Kieffer A, et al. Trends in healthcare utilization and costs associated with acute otitis media in the United States during 2008-2014. BMC Health Serv Res 2018;18:318.

2 van den Broek d'Obrenan J, Verheij TJM, Numans ME, et al. Antibiotic use in Dutch primary care: relation between diagnosis, consultation and treatment. J Antimicrob Chemother 2014:69:1701-7.

3 Rovers MM, Glasziou P, Appelman CL, et al. Antibiotics for acute otitis media: a meta-analysis with individual patient data. Lancet 2006;368:1429-35.

4 Smith L, Ewings P, Smith C, et al. Ear discharge in children presenting with acute otitis media: observational study from UK general practice. Br J Gen Pract 2010;60:101-5.

5 Centre for Clinical Practice at NICE (UK). Guideline, otitis media (acute): antimicrobial prescribing, 2018. Available: https://www.nice. org.uk/guidance/ng91/resources/otitis-media-acute-antimicrobialprescribing-pdf-1837750121413 [Accessed 30 Sep 2021].

6 RAMJ D, Venekamp RP, Eekhof J. NHG-Standaard otitis media acuta bij kinderen (derde herziening). Huisarts Wet 2014;57:648 https:// www.henw.org/archief/volledig/id5928-nhg-standaard-otitis-mediaacuta-bij-kinderen-derde-herziening.html

7 Venekamp RP, Sanders SL, Glasziou PP, et al. Antibiotics for acute otitis media in children. Cochrane Database of Systematic Reviews 2015;303:CD000219.

8 Laxminarayan R, Duse A, Wattal C, et al. Antibiotic resistance-the need for global solutions. Lancet Infect Dis 2013:13:1057-98.

9 Costelloe C, Metcalfe C, Lovering A, et al. Effect of antibiotic prescribing in primary care on antimicrobial resistance in individual patients: systematic review and meta-analysis. BMJ 2010;340:c2096.
10 Ohyama M, Furuta S, Ueno K, et al. Ofloxacin otic solution in patients with otitis media: an analysis of drug concentrations. Arch Otolaryngol Head Neck Surg 1999;125:337-40.

11 Weber PC, Roland PS, Hannley M, et al. The development of antibiotic resistant organisms with the use of ototopical medications. Otolaryngol Head Neck Surg 2004;130:S89-94.

12 van Dongen TMA, van der Heijden GJMG, Venekamp RP, et al. A trial of treatment for acute otorrhea in children with tympanostomy tubes. N Engl J Med 2014;370:723-33.

13 van Dongen TMA, Schilder AGM, Venekamp RP, et al. Costeffectiveness of treatment of acute otorrhea in children with tympanostomy tubes. Pediatrics 2015;135:e1182-9.

14 Venekamp RP, Prasad V, Hay AD. Are topical antibiotics an alternative to oral antibiotics for children with acute otitis media and ear discharge? BMJ 2016;352:i308.

15 Curtis K, Moore M, Cabral C, et al. A multi-centre, pragmatic, threearm, individually randomised, non-inferiority, open trial to compare immediate orally administered, immediate topically administered or delayed orally administered antibiotics for acute otitis media with discharge in children: The Runny Ear Study (REST): study protocol. Trials 2020;21:463

16 Ngo CC, Massa HM, Thornton RB, et al. Predominant bacteria detected from the middle ear fluid of children experiencing otitis media: a systematic review. PLoS One 2016;11:e0150949.

17 Hullegie S, Venekamp RP, van Dongen TMA, et al. Prevalence and antimicrobial resistance of bacteria in children with acute otitis media and ear discharge: a systematic review. Pediatr Infect Dis $J$ 2021:40:756-62.

18 Roland PS, Anon JB, Moe RD, et al. Topical ciprofloxacin/ dexamethasone is superior to ciprofloxacin alone in pediatric patients with acute otitis media and otorrhea through tympanostomy tubes. Laryngoscope 2003;113:2116-22.

19 Roland PS, Kreisler LS, Reese B, et al. Topical ciprofloxacin/ dexamethasone otic suspension is superior to ofloxacin otic solution in the treatment of children with acute otitis media with otorrhea through tympanostomy tubes. Pediatrics 2004;113:e40-6.

20 Boyd NH, Gottschall JA. Assessing the efficacy of tragal pumping: a randomized controlled trial. Otolaryngol Head Neck Surg 2011:144:891-3.

21 Suzuki HG, Dewez JE, Nijman RG, et al. Clinical practice guidelines for acute otitis media in children: a systematic review and appraisa of European national guidelines. BMJ Open 2020;10:e035343

22 Nederlands Kenniscentrum voor Farmacotherapie bij Kinderen, Kinderformularium. Available: https://www.kinderformularium.nl/ geneesmiddel/7/amoxicilline [Accessed 18 Mar 2021].

23 Little P, Gould C, Williamson I, et al. Pragmatic randomised controlled trial of two prescribing strategies for childhood acute otitis media. BMJ 2001;322:336-42.

24 Watson L, Little P, Moore M, et al. Validation study of a diary for use in acute lower respiratory tract infection. Fam Pract 2001;18:553-4.

25 Rosenfeld RM, Goldsmith AJ, Tetlus L, et al. Quality of life for children with otitis media. Arch Otolaryngol Head Neck Surg 1997;123:1049-54.

26 Bouwmans C, Hakkaart-van Roijen L, Koopmanschap M. Manual of the iMTA productivity cost questionnaire (iPCQ). Rotterdam: iMTA. Rotterdam: Erasmus University, 2013. www.imta.nl

27 van Staaij BK, Rovers MM, Schilder AG, et al. Accuracy and feasibility of daily infrared tympanic membrane temperature measurements in the identification of fever in children. Int $J$ Pediatr Otorhinolaryngol 2003;67:1091-7.

28 Engel J, Anteunis L, Volovics A, et al. Prevalence rates of otitis media with effusion from 0 to 2 years of age: healthy-born versus high-riskborn infants. Int J Pediatr Otorhinolaryngol 1999;47:243-51.

29 O'Brien KL, Nohynek H. World Health Organization Pneumococcal Vaccine Trials Carriage Working Group. Report from a WHO Working Group: standard method for detecting upper respiratory carriage of Streptococcus pneumoniae. Pediatr Infect Dis J 2003;22:e1-11.

30 van Schaik W. The human gut resistome. Philos Trans $R$ Soc Lond $B$ Biol Sci 2015;370:20140087.

31 Wangge G, Klungel $\mathrm{OH}$, Roes $\mathrm{KCB}$, et al. Interpretation and inference in noninferiority randomized controlled trials in drug research. Clin Pharmacol Ther 2010;88:420-3.

32 U.S. Department of Health and Human Services, Food and Drug Administration, Center for Drug Evaluation and Research (CDER), Center for Biologics Evaluation and Research (CBER). NonInferiority Clinical Trials to Establish Effectiveness. Guidance for Industry 2016.

33 Wangge G, Klungel $\mathrm{OH}$, Roes $\mathrm{KCB}$, et al. Room for improvement in conducting and reporting non-inferiority randomized controlled trials on drugs: a systematic review. PLoS One 2010;5:e13550. 
34 Piaggio G, Elbourne DR, Pocock SJ, et al. Reporting of noninferiority and equivalence randomized trials: extension of the CONSORT 2010 statement. JAMA 2012;308:2594-604.

35 Schulz KF, Altman DG, Moher D, et al. CONSORT 2010 statement: updated guidelines for reporting parallel group randomised trials. BMJ 2010;340:c332.

36 Donders ART, van der Heijden GJMG, Stijnen T, et al. Review: a gentle introduction to imputation of missing values. J Clin Epidemiol 2006;59:1087-91.

37 Rubin D. Multiple imputation for non-response in surveys. New York: John Wiley, 1987.

38 Nederland Z. Kostenhandleiding: Methodologie van kostenonderzoek en referentieprijzen voor economische evaluaties in de gezondheidszorg. Diemen: Zorginstituut Nederland, 2016.

39 Nederland Z. Richtlijn voor het uitvoeren van economische evaluaties in de gezondheidszorg. Diemen: Zorginstituut Nederland, 2016.
40 Farmacotherapeutisch Kompas - CVZ. Available: http://www.fk.cvz. $\mathrm{nl} /$

41 Buskens E, van Staaij B, van den Akker J, et al. Adenotonsillectomy or watchful waiting in patients with mild to moderate symptoms of throat infections or adenotonsillar hypertrophy: a randomized comparison of costs and effects. Arch Otolaryngol Head Neck Surg 2007;133:1083-8.

42 National Institute for Family Finance Information website. Available: https://www.nibud.nl/beroepsmatig/

43 Hay AF, Moore M, Taylor J. Results, lessons learned and recommendations from the REST randomised controlled trial of antibiotic strategies for children with acute otitis media with discharge. 2021 Submitted to Health Technol Assess; provisionally accepted 2021

44 Moustgaard H, Clayton GL, Jones HE, et al. Impact of blinding on estimated treatment effects in randomised clinical trials: metaepidemiological study. BMJ 2020;368:I6802. 